\title{
OntoAndalus: an ontology of Islamic artefacts for terminological purposes
}

\author{
Bruno Almeida ${ }^{\mathrm{a},{ }^{*}}$ and Rute Costa ${ }^{\mathrm{a}}$ \\ ${ }^{a}$ NOVA CLUNL, Centro de Linguística da Universidade NOVA de Lisboa, Portugal \\ E-mails: brunoalmeida@fcsh.unl.pt,rute.costa@fcsh.unl.pt
}

\begin{abstract}
OntoAndalus aims at constituting a shared conceptualisation of the domain within a future multilingual terminological resource targeted at experts and students of Islamic archaeology. The present version of OntoAndalus is aligned with DOLCE+DnS Ultralite (DUL), an established top-level ontology for the Semantic Web. This article describes the modelling assumptions underlying OntoAndalus, as well as the more relevant design patterns (i.e. artefact types, events and individuals). The latter are exemplified through relevant case studies in the domain, namely those of lighting artefacts, the life cycle of pottery and the several descriptions of Vaso de Tavira.
\end{abstract}

Keywords: Ontology, terminology, artefacts, Islamic archaeology

\section{Introduction}

The challenges of developing multilingual terminological resources in the Semantic Web and integrating them in the Linked Open Data Cloud have led to ever closer ties between terminology and ontology engineering [1-3]. As of late, computational ontologies have been put forward as building blocks of knowledge-based terminological resources, from healthcare and medical science to cultural heritage and the humanities $[4,5]$. These resources, which have been referred to in the past as 'terminological knowledge bases' [6], are anchored on interdisciplinary work involving domain experts, terminologists/linguists and knowledge engineers. The ties drawn between terminology work and knowledge representation allow, for example, to draft natural language definitions based on formal definitions/descriptions of classes, which could lead to a greater consistency and overall quality of terminological resources. It is therefore paramount especially in multilingual terminology work - to distinguish language-specific aspects from the conceptual dimension of terminology, which pertains to extralinguistic domain knowledge [7].

\footnotetext{
${ }^{*}$ Corresponding author. E-mail: brunoalmeida @ fcsh.unl.pt.
}

This paper describes work carried out towards the creation of OntoAndalus, an ontology of alAndalusian pottery artefacts, which is a subdomain of Islamic archaeology [8]. OntoAndalus aims at constituting a shared conceptualisation of the domain, whose elements may be denoted by terms in several languages within a future ontoterminological resource. The creation of this resource is intended to meet the challenges noted by domain specialists with regard to terminological harmonisation (starting with Portuguese and Spanish) and to help further research in archaeology from an ontological point of view [9-11]. It is thought that several observations made in this paper will lead to future research in the domain (e.g. artefact functionality, composition, uncertain knowledge in artefact descriptions).

With regard to the development of OntoAndalus, a top-down approach was followed by reusing a foundational ontology, namely DOLCE+DnS Ultralite (DUL). DUL allowed for a rich conceptualisation of the domain, including important topics in archaeology such as artefact typology, events and techniques in the pottery life cycle, as well as the description of individual artefacts. This paper will expand on several ex- 
amples in each of these topics along with some basic assumptions about the domain. ${ }^{1}$

The paper is structured as follows. Section 2 describes the modelling process and explains the assumptions made in OntoAndalus with regard to some of the more important concepts in artefact description (e.g. parts, qualities). Section 3 details the main design patterns which were followed based on several examples. Finally, Section 4 provides a few notes on evaluation.

\section{Modelling assumptions}

OntoAndalus was developed from the interpretation of a Portuguese and Spanish corpus of specialised texts in the domain of interest, along with English textbooks and reference works. The more specialised texts consist of conference papers, journal articles, theses and monographs in which the description, typology and terminology of Islamic pottery artefacts is heavily featured as a subject matter. The artefact typologies of the CIGA group [11] and of Rosselló-Bordoy [12, 13] were especially important in order to put forward a unified typology of artefacts.

Protégé [14] was used for developing the ontology, while OWL was chosen as a modelling language. This is thought to promote interoperability with Semantic Web and Linked Data technologies, which could, in turn, facilitate the integration of OntoAndalus as the conceptual backbone of a future ontoterminological resource in the domain of interest.

DOLCE+DnS Ultralite (DUL) was selected as the foundational ontology for the development of OntoAndalus. DUL allows for a rich conceptualisation of the domain while also taking into account more practical considerations of ontology development (e.g. interoperability in the Semantic Web). DUL is a streamlined version of DOLCE-Lite, the original translation of DOLCE into OWL. Compared to DOLCE-Lite, DUL features more accessible terminology, a lighter axiomatisation and integrates a constructive Descriptions and Situations module for social and cognitive entities [15]. The latter was especially important for modelling individual artefact descriptions (Section 3.3).

OntoAndalus is developed based on the latest available version of DUL (3.31), which is imported by Protégé through the owl:imports object property. On-

\footnotetext{
${ }^{1}$ The ontology file is available at: https:/github.com/ brunoalmeida81/OntoAndalus.
}

toAndalus is made available as a separate OWL file in the RDF/XML standard containing all of the domainspecific ontology elements. Identifiers are assigned in English to each element in order to facilitate international communication. The same naming conventions as DUL are followed:

- Classes are named in upper camel case (e.g. PotteryArtefact);

- Object properties are named in lower camel case (e.g. hasFunction);

- Individuals are named in lowercase with underscores (e.g. al_andalus).

Labels in Portuguese and Spanish are assigned to the core elements of the ontology, such as the classes representing artefact types. These labels - declared through the rdfs:label property - are based on term usage observed in the corpus and may prove helpful in future discussions with Portuguese and Spanish archaeologists.

Natural language definitions of classes are also included in Portuguese and Spanish through the skos:definition property. These definitions are based on the formal descriptions/definitions of classes, which rely on object property restrictions. The same approach is followed with regard to descriptions of individuals, which is exemplified in the ontology with the case of Vaso de Tavira (Section 3.3).

\subsection{Classes and collections}

It is generally accepted that there are several categories of archaeological data to take into consideration in research design [16]. These include some basic concepts in archaeology, such as those of artefact and ecofact. From an ontological point of view, these categories of archaeological data are roles assumed by material objects. Roles are a major category of antirigid concepts in ontology design, which is exemplified in the OntoClean method for analysing subsumption hierarchies [17]. Therefore, a distinction should be made between 'artefact' in the anti-rigid sense of 'archaeological artefact' from 'artefact' in the rigid sense of 'designed artefact'. No object is necessarily an archaeological artefact, only becoming one under certain conditions and for a certain period of its existence, e.g. after being recognised as an evidence of material culture in an archaeological site. On the other hand, it does not seem that an object can stop being an artefact in the rigid sense without ceasing to exist. 
Going back to the categories of archaeological data, OntoAndalus, assumes ArchaeologicalDatum as the top role class, which is subsumed by dul:PhysicalObject. In turn, ArchaeologicalDatum subsumes ArchaeologicalArtefact, ArchaeologicalEcofact and ArchaeologicalFeature, which correspond to the main categories put forward in archaeological theory.

The concept of artefact in archaeology is broader in some respects than the constructs defined in DUL for artefactual objects, namely the classes dul:PhysicalArtifact and dul:DesignedArtifact. In DUL, a physical artefact is a physical object described by a plan and which has a specific goal. This is meant to include the intentional selection of natural objects, as when someone selects a pebble with the purpose of using it as a paperweight. In this example, the paperweight could be considered as an instance of dul:PhysicalArtifact. On the other hand, a designed artefact in DUL is also described by a design, thus excluding the selection of natural objects. It may, however, include cases where an artefact is given new functionality. For example, if an old cradle is repurposed as a flowerpot, the newly-created object can be considered as an instance of dul:DesignedArtifact [15].

In archaeology, however, fragments of designed artefacts, such as potsherds, are considered to be themselves artefacts. Potsherds can also be the subject of classification schemes based, for example, on their clay paste or decorative technique. It is clear, however, that a potsherd is not something intentionally made or selected and, therefore, does not instantiate either dul:PhysicalArtifact or dul:DesignedArtifact. Although the description of potsherds will not be further exemplified in this article, OntoAndalus includes some predicates for this use case. The class Potsherd is subsumed by DesignedArtefactFragment, along with the object properties hasFragment and its inverse isFragmentOf, both having dul:PhysicalObject as domain and range.

With regard to the descriptions of the relevant classes of archaeological data, the following is proposed:

- ArchaeologicalDatum rdfs:subClassOf dul:PhysicalObject and isFoundln some ArchaeologicalSite. An archaeological datum is a physical object found in some archaeological site;

- ArchaeologicalArtefact rdfs:subClassOf (dul:DesignedArtifact or DesignedArtefactFragment) and ArchaeologicalDatum and isRecoveredThrough some ExcavationEvent. An artefact is a designed object, or fragment thereof, which is an archaeological datum recovered through an excavation event;

- ArchaeologicalEcofact rdfs:subClassOf dul:PhysicalBody and ArchaeologicalDatum and isRecoveredThrough some ExcavationEvent. An ecofact is a physical body, i.e. a natural object, which is an archaeological datum recovered through an excavation event;

- ArchaeologicalFeature rdfs:subClassOf dul:PhysicalObject and isContextOf (Artefact or Ecofact) and ArchaeologicalDatum. A feature is the archaeological context of an artefact or ecofact, such as a grave, ditch, mound, wall, hearth. Contrary to artefacts and ecofacts, features are nonremovable elements of archaeological sites and, therefore, are not recovered through excavations.

Since OntoAndalus is focussed on pottery, it is assumed that archaeological artefacts only include designed objects or their fragments. On the other hand, intentionally selected natural objects would be considered as ecofacts.

OntoAndalus further includes the PotteryArtefact class, which has the following description: dul:DesignedArtifact and dul:hasConstituent some ClayPaste and dul:isParticipantln some PotteryArtefactManufactureEvent. A pottery artefact is a designed artefact constituted by an amount of clay which undergoes a manufacture event. $^{2}$

While the objects in our domain of discourse are archaeological pottery artefacts, the typology put forward in OntoAndalus is a specialisation of dul:DesignedArtifact. This is justified by the fact that domain specialists are interested in which types the objects fall under (e.g. lamp, bowl), while classes such as 'pottery lamp' or 'archaeological pottery lamp' would serve no purpose in artefact typology.

It is standard practice in our domain of interest to classify artefact types according to their function, e.g. as tableware, transportation or lighting objects [11]. In OntoAndalus, this is achieved through collections, which are modelled as instances of dul:Collection (Fig. 1). Artefact types can then be placed within a collection through the dul:isMemberOf object property.

The use of collections avoids overloading the artefact typology with unnecessary classes, e.g. 'tableware objects'. It also simplifies the hierarchy consid-

\footnotetext{
${ }^{2}$ The pottery manufacture event is further described in Section
} 3.2 .
1 


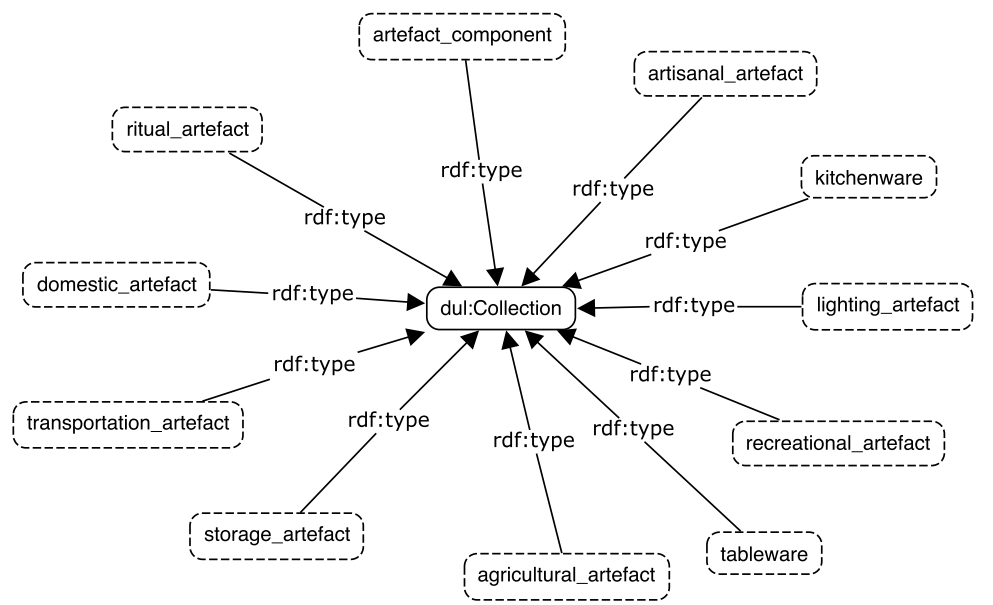

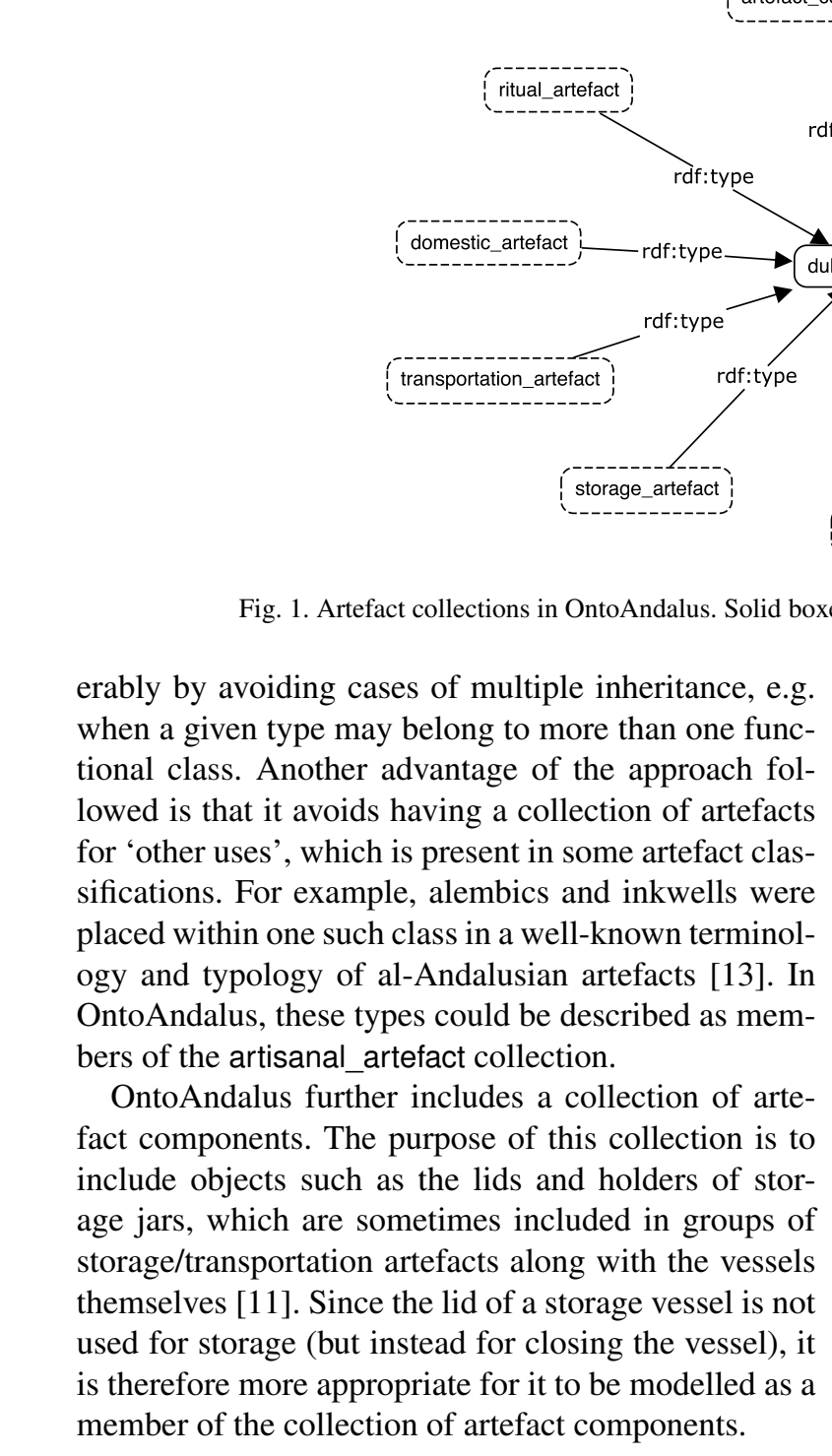

\subsection{Parts and dependent places}

OntoAndalus makes use of the simple hierarchy of part-whole object properties of DUL. The object property dul:hasPart corresponds to the most generic parthood relation, which is transitive and has its domain and range set to the root class dul:Entity. DUL also includes dul:hasComponent, which is a non-transitive parthood relation. The latter may be used to model an immediate parthood relation between two objects or between a whole and its functional or assembly components.

Parthood further raises the questions of overlap and boundaries. DUL includes the symmetric object prop- erty dul:hasCommonBoundary, which can be used to represent contiguity between parts of an object. Furthermore, the symmetric dul:overlaps object property may be used to represent 'fuzziness' between connected parts (e.g. 'the chest overlaps with the abdomen').

Still on the topic of parts, OntoAndalus follows the basic distinction between parts defined by fiat and bona fide boundaries [18]. This approach is also followed in the original version of DOLCE [19] and in the CIDOCCRM ontology [20]. Physical features are parts of objects which are arbitrarily delimited. In contrast, independent physical objects are delimited by bona fide boundaries, such as physical gaps or material discontinuities. Therefore, a lid and a pot are independent objects, since they are separated by a bona fide boundary. However, the lid remains part of the pot as an artefact. On the other hand, the lip and the rim of a jar are fiat objects, since they are determined through fiat boundaries in a bode fide object.

Based on the original hierarchy of features in DOLCE, the RelevantPart class has been included in OntoAndalus. DOLCE also had a class for 'dependent places', such as holes in a piece of cheese or the space underneath a table. In DUL, these entities seem to fall within the dul:Place class in the hierarchy of social objects. 'Places', in this sense, are not considered to be parts of material objects, but rather immaterial entities located in or around other entities. This includes sites, complements of physical objects and geopolitical entities.

With regard to the specialisation of RelevantPart, OntoAndalus includes several classes based on a review of literature in the domain $[11,21,22]$. The most 


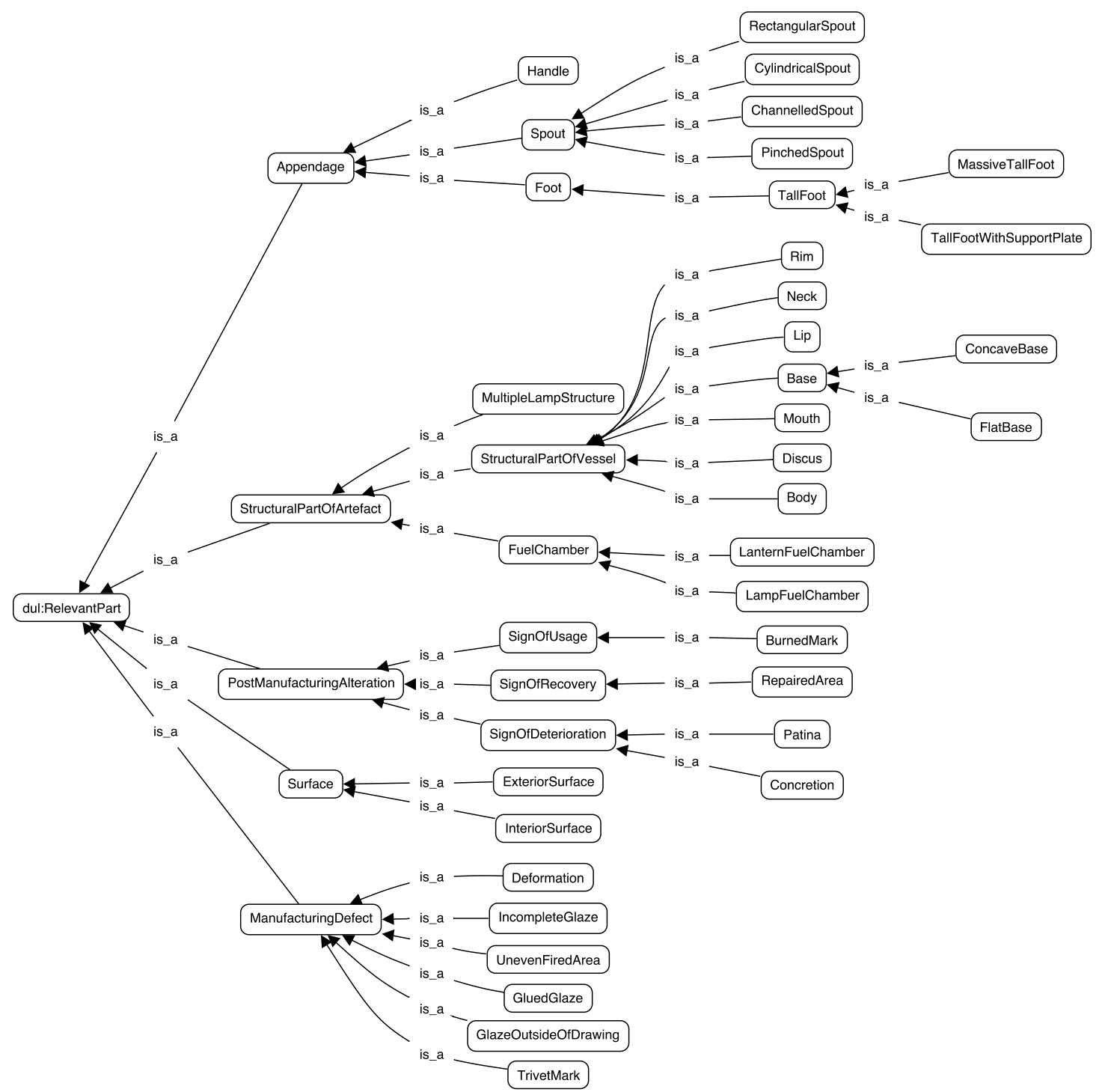

Fig. 2. Class hierarchy of RelevantPart. The is_a label represents the rdfs:subClassOf property.

relevant classes in this hierarchy include the structural parts of vessels (Fig. 2).

Orifice, body and base are usually seen as the primary features of a vessel (Fig. 3) [22]. The body is generally understood to be the part of the vessel between the base and the orifice which includes the area of maximum diameter (or greatest enclosed volume). The orifice, or mouth, may be restricted if its diameter is less than the maximum diameter of the vessel, or unrestricted if its diameter is equal or greater than the maximum diameter of the vessel. The overall shape of a vessel is often described as closed if it has a restricted orifice. Otherwise, the vessel is said to be open. In our domain of interest, this practice is generally adopted by the Portuguese and Spanish archaeologists, who refer to open and closed forms rather than restricted and unrestricted orifices $[11,13,21]$.

Vessel shapes are often more complex, leading to several possible configurations of parts. In closed forms, the area between the point of maximum diameter and the orifice or neck can be referred to as 'shoulder' or 'upper body', while the area below the point of maximum diameter is the lower body. Another relevant feature of some vessel shapes is the extension of the orifice through a neck. The neck is can be understood as a restriction of the opening of the vessel, extending 

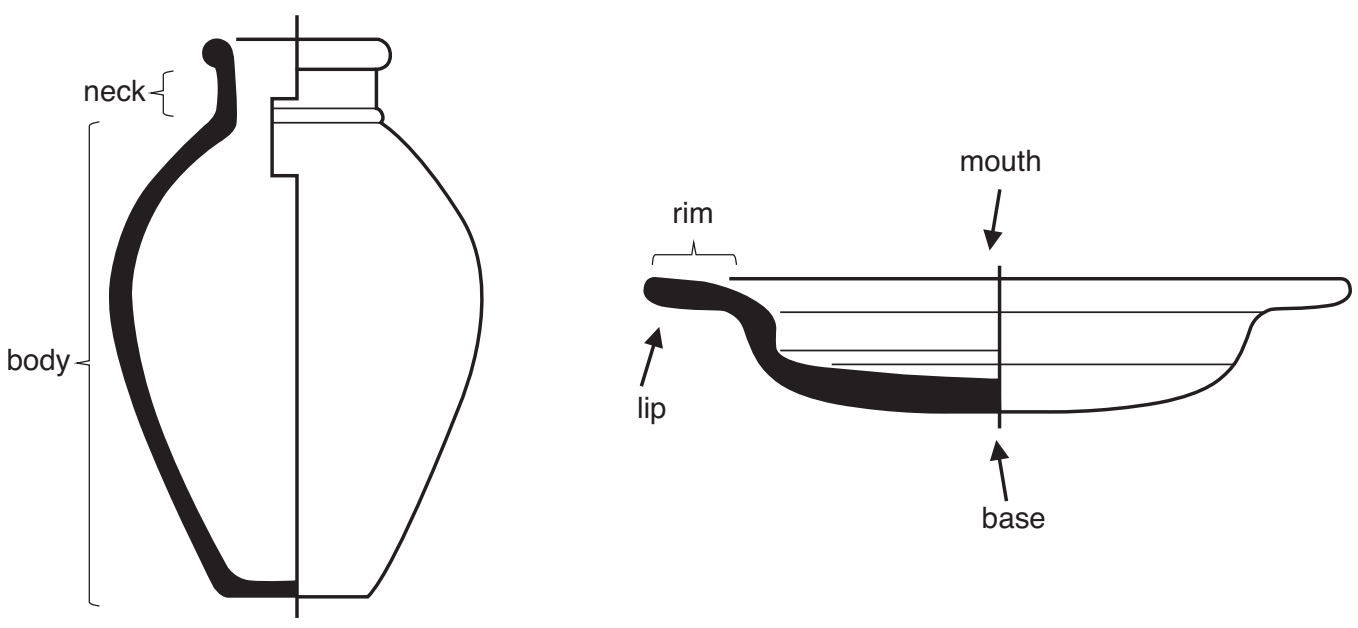

Fig. 3. Salient vessel parts. Vector illustrations by Mariana Tavares.

somewhere after the point of maximum diameter of the body [22].

The final salient feature of a vessel is the base, i.e. the underside of a vessel. However, it is sometimes difficult to distinguish the base from the body in roundshaped vessels, in which the base would correspond to a very small area in the underside of the vessel [22].

Secondary features include appendages, which may be applied to several parts of a vessel (e.g. feet, handles, spouts), as well as the rim and the lip. The latter two features are parts of the mouth: while the rim is the innermost part, the lip corresponds to the outward edge of the mouth [22].

Body will be shown as an example of how these entities can be modelled in OntoAndalus. As previously mentioned, the body is the part of a vessel between the base and rim (or neck, if there is one). The dul:overlaps object property can be used to represent the fact that the borders between these entities are not clear cut. The following description of Body is put forward in OntoAndalus:

- Body rdfs:subClassOf StructuralPartOfVessel and ((dul:overlaps some (Rim or Neck)) and (dul:overlaps some Base)

The intended definition of Body in English is 'structural part of a vessel located between the base and rim (or neck).'

The functional components of artefacts is a further topic of interest in OntoAndalus. For example, instances of the Lamp class are often described by archaeologists as having a closed (i.e. restricted) fuel chamber, which corresponds structurally to the vessel without any appendages $[11,21]$. The following de- scription of LampFuelChamber is put forward in OntoAndalus:

- LampFuelChamber rdfs:subClassOf FuelChamber and hasFunction some containing_liquid_fuelfor_lighting and isComponentOf some Lamp

The intended definition of LampFuelChamber in English is 'component of a pottery lamp with the function of containing liquid fuel for lighting'.

Besides structural parts, the RelevantPart class includes typical features (e.g. surfaces, scratches, spots). The Surface, ManufacturingDefect and PostManufacturingAlteration classes were included in OntoAndalus, based on the literature of the domain [11, 21]. These classes enable the modelling of relevant features such as the interior and exterior surfaces of artefacts, deformed or uneven-fired areas and burned marks.

A further issue lies in the relationship between parts of artefacts and non-material spaces bounded by these parts. In ontological literature, holes have been considered as 'superficial entities' located in their physical hosts [23]. Following this insight, OntoAndalus distinguishes between the orifice and the mouth of a vessel, in that the former is a part of the vessel and the latter is a non-material space located in the vessel. According to this distinction, the orifice can be understood as the part of the interior space of the vessel bounded by the mouth. In OntoAndalus, spaces are modelled as subclasses of dul:Place in the hierarchy of social objects. The following definition of Mouth is put forward in OntoAndalus:

- Mouth rdfs:subClassOf StructuralPartOfVessel and dul:hasPart some Lip and dul:hasPart some Rim 
and dul:hasCommonBoundary some VesselOrifice

The mouth is therefore understood as a structural part of a vessel, composed of a lip and rim, having a common boundary with a vessel's orifice. The following description of VesselOrifice is put forward:

- VesselOrifice rdfs:subClassOf dul:Place and dul:hasLocation some Vessel and dul:hasCommonBoundary some Mouth

\subsection{Qualities and attributes}

One of the more characteristic aspects of DOLCE lies in the distinction between the qualities of individuals (e.g. colour, shape) and their abstract values, which may change over time (e.g. red, round) [19]. In DUL, qualities can be represented as classes and attributes as individuals instantiating the dul:Region class (or a subclass thereof). The object properties dul:hasQuality and dul:hasRegion can be used to establish the required links. For example:

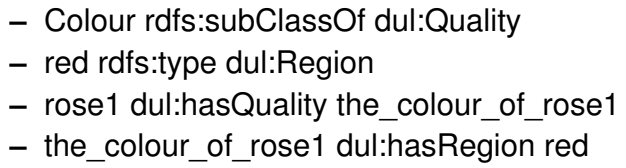

While this approach is precise when it comes to describing individual qualities, its application for the definition of concepts is less straightforward. However, DUL allows to link any entity to an abstract region through the dul:hasRegion object property. The latter may specialise further object properties restricted to subclasses of dul:Region. For example, the hasShape object property is asserted in OntoAndalus, allowing for a direct link between physical objects and the ShapeAttribute region. Individual shapes are then represented as instances of the latter class. The specialisation of dul:hasRegion in OntoAndalus is illustrated in Fig. 4.

The approach followed in OntoAndalus with regard to qualities can be illustrated with the case of function. It is assumed in OntoAndalus that functions inhere in artefacts similarly to standard examples of qualities, such as colour or shape. This is partly inspired by Basic Formal Ontology, where both functions and qualities are seen as dependent continuants [24].

The FunctionalAttribute class is included in the hierarchy of abstract regions of OntoAndalus, where different spaces are modelled as individuals. The functional_space individual represents the maximal region

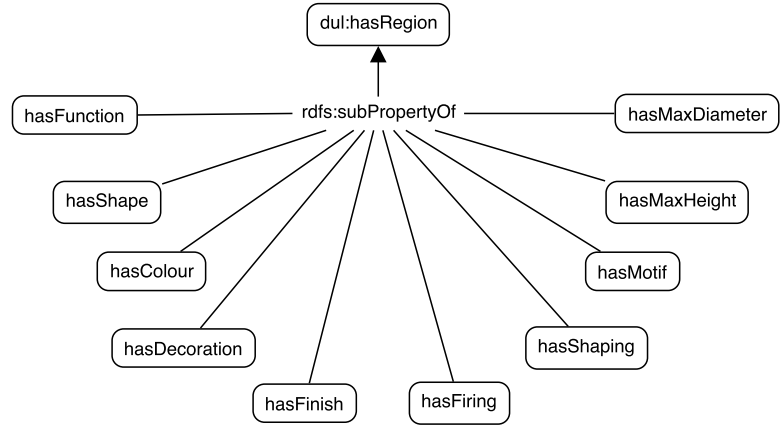

Fig. 4. Specialisation of the dul:hasRegion object property.

in which functions are to be modelled. The former is related through the generic parthood relation to other individuals and so consecutively until reaching the most specific functions (Fig. 5).

Individuals within this space are used in formal descriptions of artefact types. This approach is based on Rice's analysis of pottery vessel functionality [22]. The containing_things individual represents the most generic function of a vessel. It is further specialised into the utilitarian functions of transfer (e.g. canteens, serving dishes), storage (e.g. storage pots, shipping containers) and processing (e.g. lamps, cooking pots). It is possible for functions to overlap, e.g. longdistance transfer could also imply a storage function.

Special purpose, or non-utilitarian, functions can also be defined in OntoAndalus, such as display (e.g. the function of an elite object with an elaborate decoration) and ceremonial use (e.g. a vessel for ritual ablutions). Since parts of the functional space may overlap, it is possible for a function to be partly included in both utilitarian and non-utilitarian regions. For example, ritual ablutions are a specialisation of washing and, therefore, could also be seen as a processing function.

\section{Main design patterns}

\subsection{Artefact types}

In this section, the case of lighting artefacts will be described as an example of how artefact types can be modelled in OntoAndalus. Lighting artefacts were chosen as a case study because they include some of the more best-known and representative artefacts of the Islamic period in the Iberian Peninsula.

According to Gómez Martínez [21], archaeologists usually recognise four series (i.e. pottery types) within 


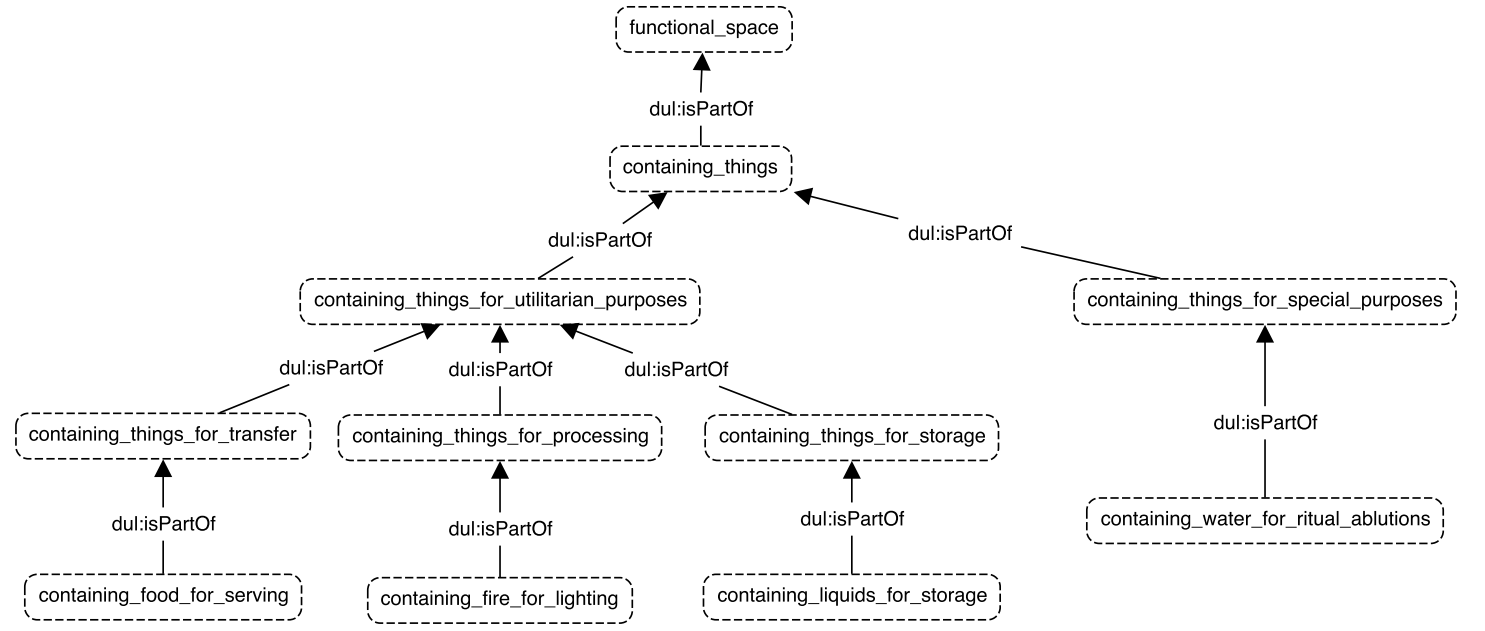

Fig. 5. Section of the functional space.

the lighting objects of the al-Andalus. These are denoted by the following Spanish terms: (i) candil; (ii) policandela (or almenara); (iii) lamparilla; and (iv) fanal (or linterna) (Fig. 6).

There is some controversy among scholars regarding the definition of at least two of these pottery series, namely the lamparilla and the almenara. The lamparilla series was first defined by Valdés Fernández in his "Kalifale Lampen" article, published in Madrider Mitteilungen in 1984 [21, 25]. Valdés argued that certain pottery vessels found in the Madinat al-Zahra site (near present-day Cordoba, Spain) were used for lighting. This hypothesis was based on the resemblance of the findings with Islamic glass lamps that were placed on support plates. Furthermore, while the candil is a common find in Islamic contexts, it is absent from the Madinat al-Zahra site. The lamparilla would have been part of the domestic lighting system used in the palatial city. While these objects were initially thought to be exclusive to Madinat al-Zahra, similar findings have since occurred elsewhere in the former al-Andalus [26].

Gómez Martínez tentatively proposed the existence of a bifrustum-shaped variant, which is a frequent finding in the Iberian Peninsula (Fig. 6-iii) [27]. In later works, this archaeologist expressed serious doubts with regard to the existence of the lamparilla as a lighting artefact. This was partly due to the recovered artefacts not having the expected signs of usage (i.e. burned marks). However, more importantly, since these objects are opaque (contrary to the glass lamps), they would only be effective in any sort of lighting function when completely filled with oil [21].
The controversy is different when it comes to the almenara series. Rosselló-Bordoy first defined the series as a sort of 'multiple lamp' (i.e. with multiple fuel chambers) or as a base for holding several lamps, which could be suspended from the ceiling [13]. While scholars recognise the existence of lamps with multiple fuel chambers in metal, its existence in pottery was merely deduced from potsherds. According to Gómez Martínez [21], the almenara series remains ill-defined: while it is true that some potsherds of lamp fuel chambers were part of a larger whole, its specific configuration remains largely unknown.

Since DOLCE quantifies over possible entities, there is no underlying issue in representing theoretical artefact types in OntoAndalus. The possible types of lighting artefacts were, therefore, introduced in the ontology along with the more established candil and fanal types. This has the advantage of providing more choice for particular groups of experts.

In order to facilitate communication and maintain consistency with DUL, each class is identified in English: (i) Lamp; (ii) MultipleLamp; (iii) StationaryLamp and (iv) Lantern. The suggested descriptions of these classes adhere to the following pattern: superordinate class + collection + function $+\operatorname{part}(s)$ or component(s). This pattern corresponds to the essential characteristics of each series.

The descriptions of the lighting artefact classes are as follows: 
(i)

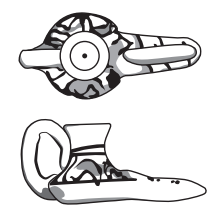

(ii)

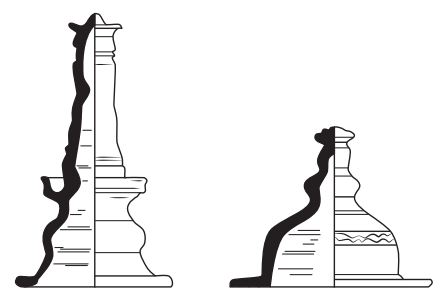

(iii)

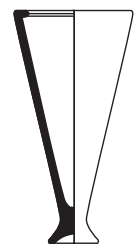

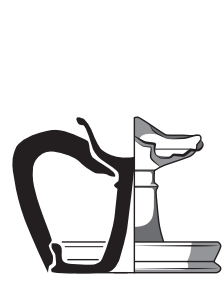
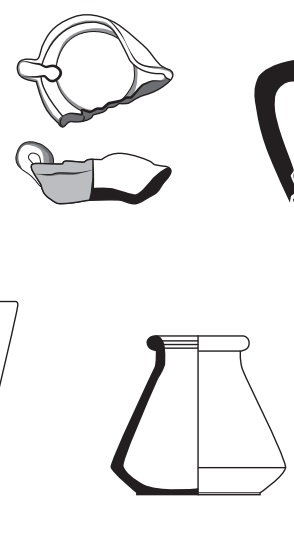

(iv)

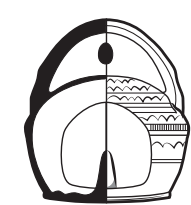

Fig. 6. Types of lighting artefacts. Vector illustrations by Mariana Tavares.

Lamp (candil). Artefact for lighting in closed spaces composed of at least one spout and a single chamber for liquid fuel. ${ }^{3}$

- Lamp rdfs:subClassOf dul:DesignedArtifact

- Lamp rdfs:subClassOf dul:isMemberOf some lighting_artefact

- Lamp rdfs:subClassOf hasFunction some containing_fire_for_lighting_in_closed_spaces_using_liquid_fuel

- Lamp rdfs:subClassOf hasComponent exactly 1 LampFuelChamber

- Lamp rdfs:subClassOf hasComponent min 1 Spout

According to the specialists, the candil was made for domestic lighting. Its typical components include a fuel chamber, a spout for holding the wick and a handle. Nevertheless, there are objects within this series that do not have handles, which were designed to be suspended. Also, less typical instances of this type may have more than one spout $[13,21,28]$.

Lantern (fanal or linterna). Artefact for lighting in open spaces composed of a single chamber for solid fuel.

- Lantern rdfs:subClassOf dul:DesignedArtifact

- Lantern rdfs:subClassOf dul:isMemberOf some lighting_artefact

\footnotetext{
${ }^{3}$ Although the qualified cardinality restriction with a minimum cardinality of 1 is logically equivalent to the existential restriction, it is nevertheless useful in helping to draft definitions in a natural language.
}

- Lantern rdfs:subClassOf hasFunction some containing_fire_for_lighting_in_open_spaces_usingsolid_fuel

- Lantern rdfs:subClassOf hasComponent exactly 1 LanternFuelChamber

This artefact type was meant for lighting in the outdoors. The fuel contained in its chamber would have been solid, e.g. wax. The typical features of the object are based on isolated findings, and include having a closed shape, globular body and a single handle $[11,21]$.

Multiple lamp (almenara, policandela). Artefact for stationary lighting in closed spaces composed of more than one chamber for liquid fuel unified by a structure.

- MultipleLamp rdfs:subClassOf dul:DesignedArtifact

- MultipleLamp rdfs:subClassOf dul:isMemberOf some lighting_artefact

- MultipleLamp rdfs:subClassOf hasFunction some containing_fire_for_stationary_lighting_in_closedspaces_using_liquid_fuel

- MultipleLamp rdfs:subClassOf hasComponent min 2 LampFuelChamber

- MultipleLamp rdfs:subClassOf hasComponent some MultipleLampStructure

The scarce information available indicates that this artefact would have had several chambers unified by some sort of structure, like a stand or a base. Furthermore, it was to be suspended or, at the very least, left stationary $[13,21]$. 


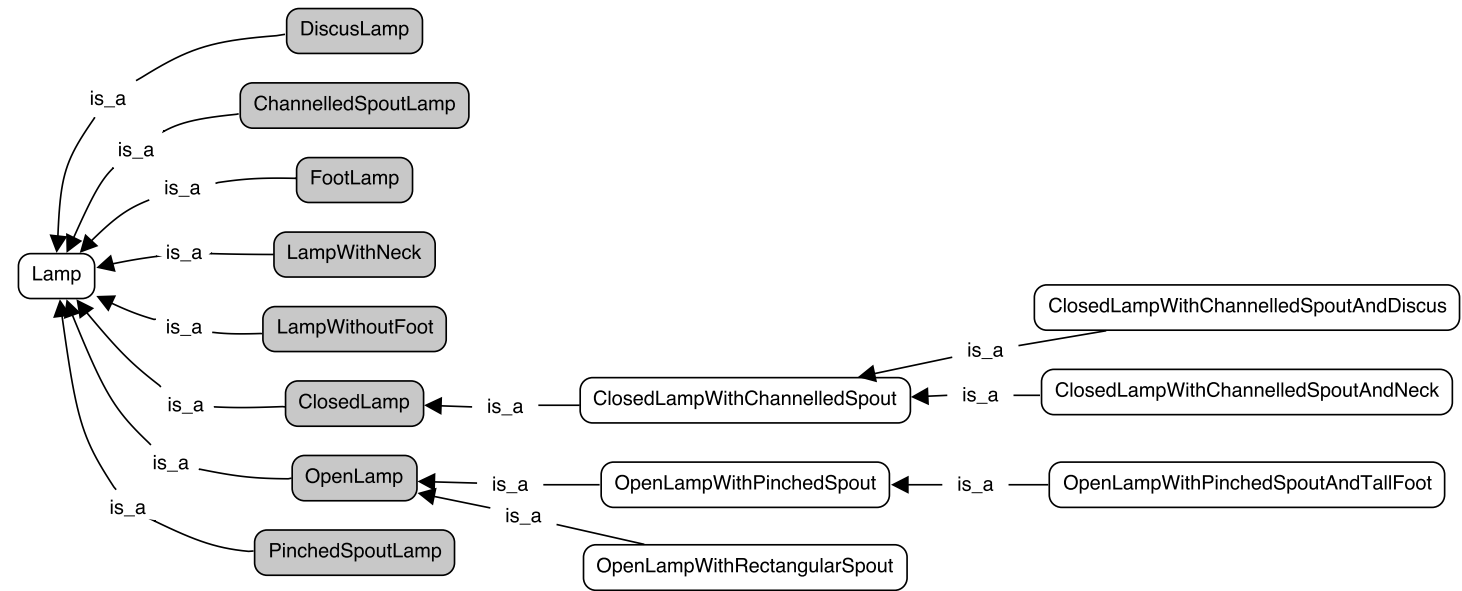

Fig. 7. Types of Lamp in the asserted hierarchy. Gray boxes indicate defined classes.

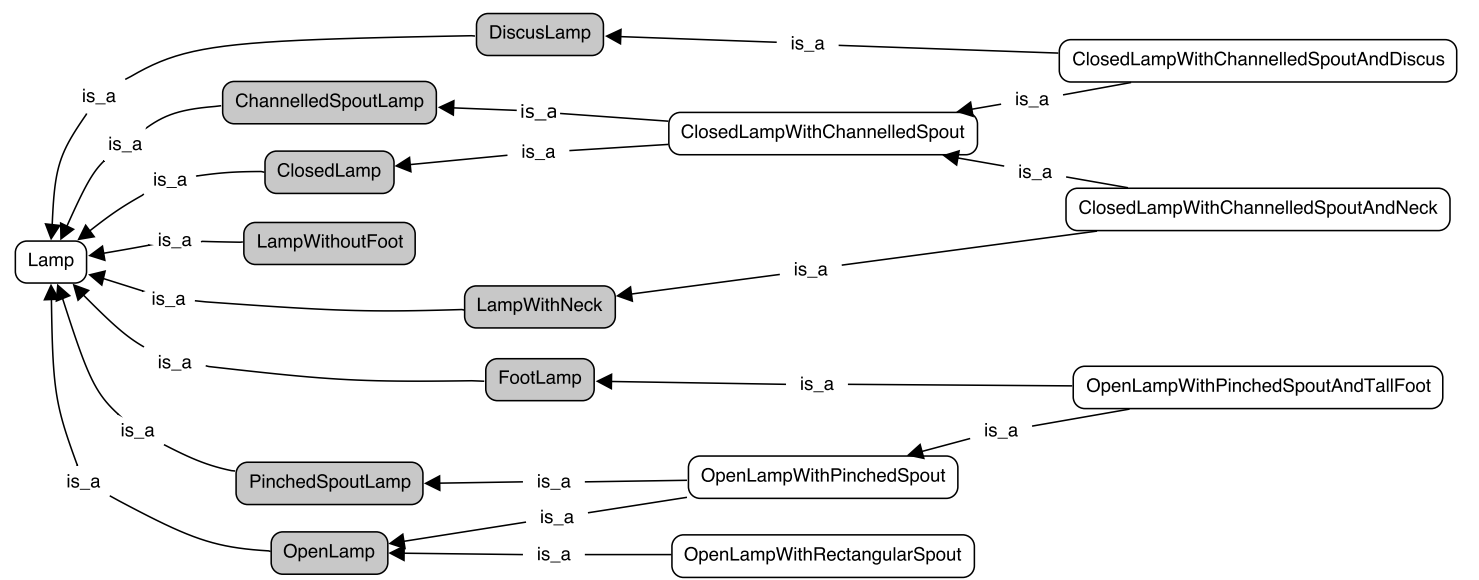

Fig. 8. Inferred hierarchy of Lamp with multiple criteria of subdivision.

Stationary lamp (lamparilla). Artefact for stationary lighting in closed spaces composed of a single chamber for liquid fuel.

- StationaryLamp rdfs:subClassOf dul:DesignedArtifact

- StationaryLamp rdfs:subClassOf dul:isMemberOf some lighting_artefact

- StationaryLamp rdfs:subClassOf hasFunction some containing_fire_for_stationary_lighting_in_closed_spaces_using_liquid_fuel

- StationaryLamp rdfs:subClassOf hasComponent exactly 1 LampFuelChamber

This hypothetical lighting artefact was either left on a table stand or on a discoidal plate, which would have held several instances [25]. In OntoAndalus, the StationaryLamp class is further divided according to shape: either inverted frustum (instantiated by the objects found in Madinat Al-Zahra) or bifrustum-shaped.

The division of the Lamp class is more complex, since there can be multiple subtypes based on criteria such as shapes (e.g. lamps with globular bodies) or appendages (e.g. lamps with tall feet). OntoAndalus includes four criteria of subdivision of the Lamp class: (i) vessel form, (ii) type of spout, (iii) inclusion of a discus or neck and (iv) inclusion of a tall foot. The multiple criteria of subdivision are represented through defined classes, which are pairwise disjoint. Since the more salient criterion for distinguishing between types of lamps is that of vessel form (i.e. open or closed), this was chosen as the primary criterion of subdivision of the Lamp class $[11,21]$. Therefore, only the disjoint classes ClosedLamp and OpenLamp are further subdivided in the asserted hierarchy of OntoAndalus, 


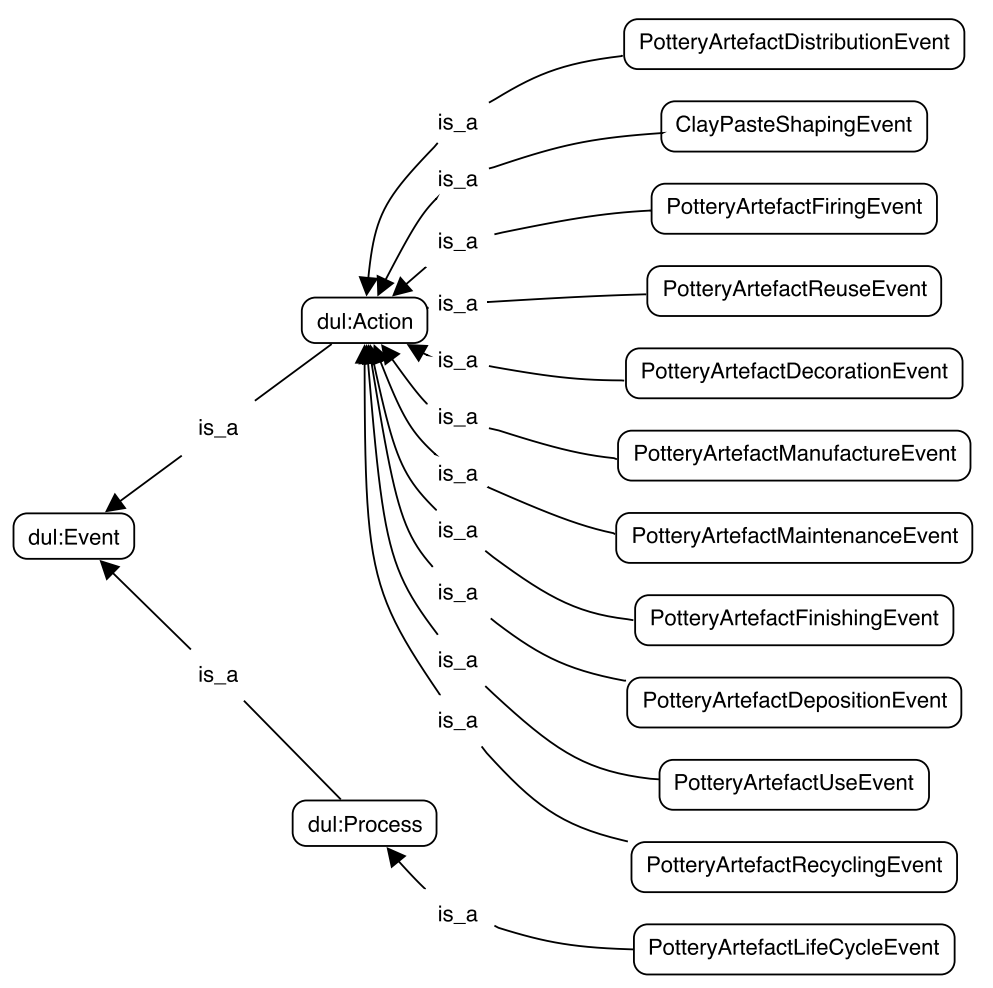

Fig. 9. Class hierarchy of events in the pottery artefact life cycle.

while the remaining classification can be inferred by a reasoner (Figs. 7, 8), which avoids overloading the asserted hierarchy with instances of multiple inheritance.

ClosedLamp and OpenLamp are divided according to the type of spout. In the case of the closed variant, this spout is labelled in the ontology as a "channelled spout'. In Spanish archaeological literature, it is often referred to as pico de piquera (or simply as piquera) [21]. Although it may vary in size and shape (e.g. more or less elongated, with straight or curved walls), it has been represented as a single type of spout in OntoAndalus. Other variants can be modelled as subclasses of ChannelledSpout (e.g. ShortChannelledSpout). The ClosedLampWithChannelledSpout class is further divided based on whether the artefact includes a neck or a discus. Lastly, the open forms may have a pinched spout or, in some cases, a small rectangular spout is added to the chamber. An important variant of the open lamp with pinched spout includes a tall foot with support plate.

\subsection{Events and tasks}

When it comes to events, DUL distinguishes between actions and processes. The former require at least one agent executing a task. Processes, on the other hand, do not strictly involve agency and are considered based on their evolution through time.

By the 'pottery life cycle' it is meant the totality of events in which individual pottery artefacts participated in. According to Schiffer [29], the life cycle of an artefact has six stages: (i) procurement of raw materials; (ii) manufacture, through various processing activities; (iii) use, whereby the artefact performs its functions; (iv) maintenance, including repair and replacement of parts; (v) reuse, whereby an artefact is repurposed for a different function; and (vi) deposition, which corresponds to the end of its use-life and integration in the archaeological record. Other relevant events in the life cycle include the distribution of newly manufactured objects to their end-users and the recycling of objects (or fragments thereof) [30].

The above-mentioned classes are modelled as temporal parts of the overarching PotteryArtefactLifeCycleEvent (Fig. 9). The latter is modelled as a process containing all of the relevant events that happen to a pottery artefact over time. Its temporal parts are actions, since they would require the participation of least one agent. 


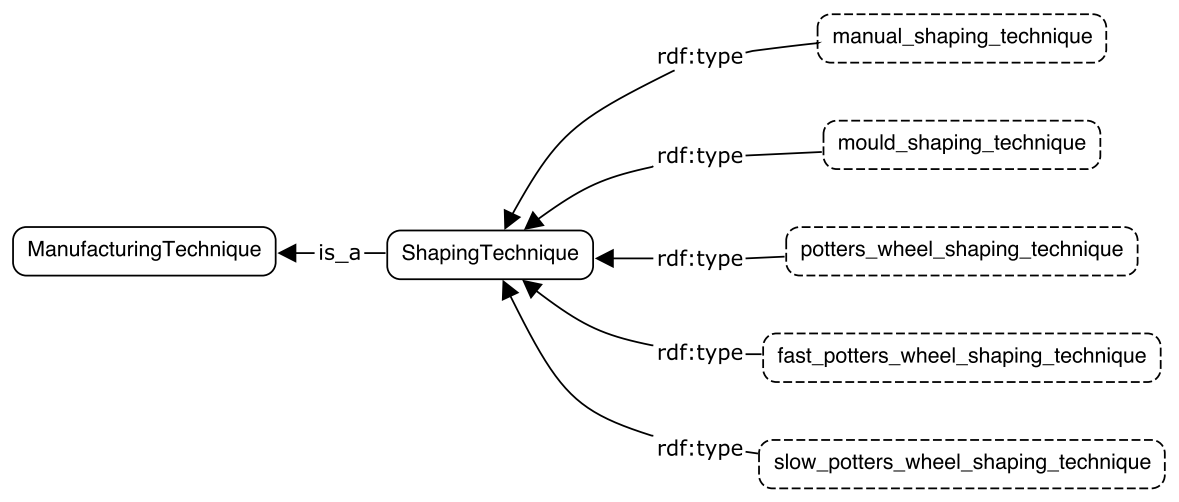

Fig. 10. Shaping techniques in OntoAndalus.

A key concept for modelling the life cycle of pottery in OntoAndalus is the PotteryArtefactManufactureEvent. The latter can be defined in English as: 'action by which a pottery artefact is manufactured, consisting of at least the stages of shaping and firing the clay paste by applying at least one manufacturing technique'. The several stages of the manufacture event are modelled as its temporal parts, namely the shaping, finishing, decoration and firing events. ClayPasteShapingEvent, for example, has the following description:

- ClayPasteShapingEvent rdfs:subClassOf Action

- ClayPasteShapingEvent rdfs:subClassOf isPartOf some PotteryArtefactManufactureEvent

- ClayPasteShapingEvent rdfs:subClassOf dul:hasParticipant some ClayPaste

- ClayPasteShapingEvent rdfs:subClassOf dul:executesTask min 1 ShapingTechnique

The intended definition in English is the following: 'action by which clay paste is shaped through the application of at least one shaping technique'.

As specified in DUL, all actions imply the participation of an agent executing at least one task. Tasks bridge the gap between the ontology of events and that of social objects, more specifically those subsumed by the dul:Concept class. Concepts, in this sense, are reified predicates that allow for the classification of entities in a ground ontology. In DUL, a task is a type of event which classifies an action. Manufacturing techniques are modelled as instances of dul:Task in OntoAndalus. Each manufacture event (including its stages) may be associated to several techniques.

Examples will be provided of how shaping and decorative techniques are represented in OntoAndalus. The former include manual shaping, mould shaping and shaping with a potter's wheel (also known as 'throwing') [11, 21] (Fig. 10). Throwing has two variants according to the type of wheel employed (slow or fast). The dul:specializes object property allows to assert that both variants are a subtype of potter_wheel_shaping_technique.

The subtype of this technique that uses a fast potter's wheel has the following description:

- fast_potters_wheel_shaping_technique rdfs:type ShapingTechnique

- fast_potters_wheel_shaping_technique dul:specializes potters_wheel_shaping_technique

- fast_potters_wheel_shaping_technique dul:hasPart shaping_of_clay_with_fast_potters_wheel

Or, in English, 'shaping technique in which a fast potter's wheel is used to give shape to the clay paste'.

Fig. 11 shows the decorative techniques present in OntoAndalus. For example, the cuerda seca technique has the following definition in English: 'decorative technique consisting of drawing motifs with an oxide manganese solution and filling the outlined spaces with a glaze substance'.

This technique has two variants, depending on whether the glaze is applied throughout the surface of the artefact (complete cuerda seca) or only partially (partial cuerda seca). The formal description of the complete variant is the following:

- complete_cuerda_seca_decorative_technique rdfs:type DecorativeTechnique

- complete_cuerda_seca_decorative_technique dul:specializes cuerda_seca_decorative_technique

- complete_cuerda_seca_decorative_technique dul:hasPart drawing_motifs_with_oxide_manganese_solution 


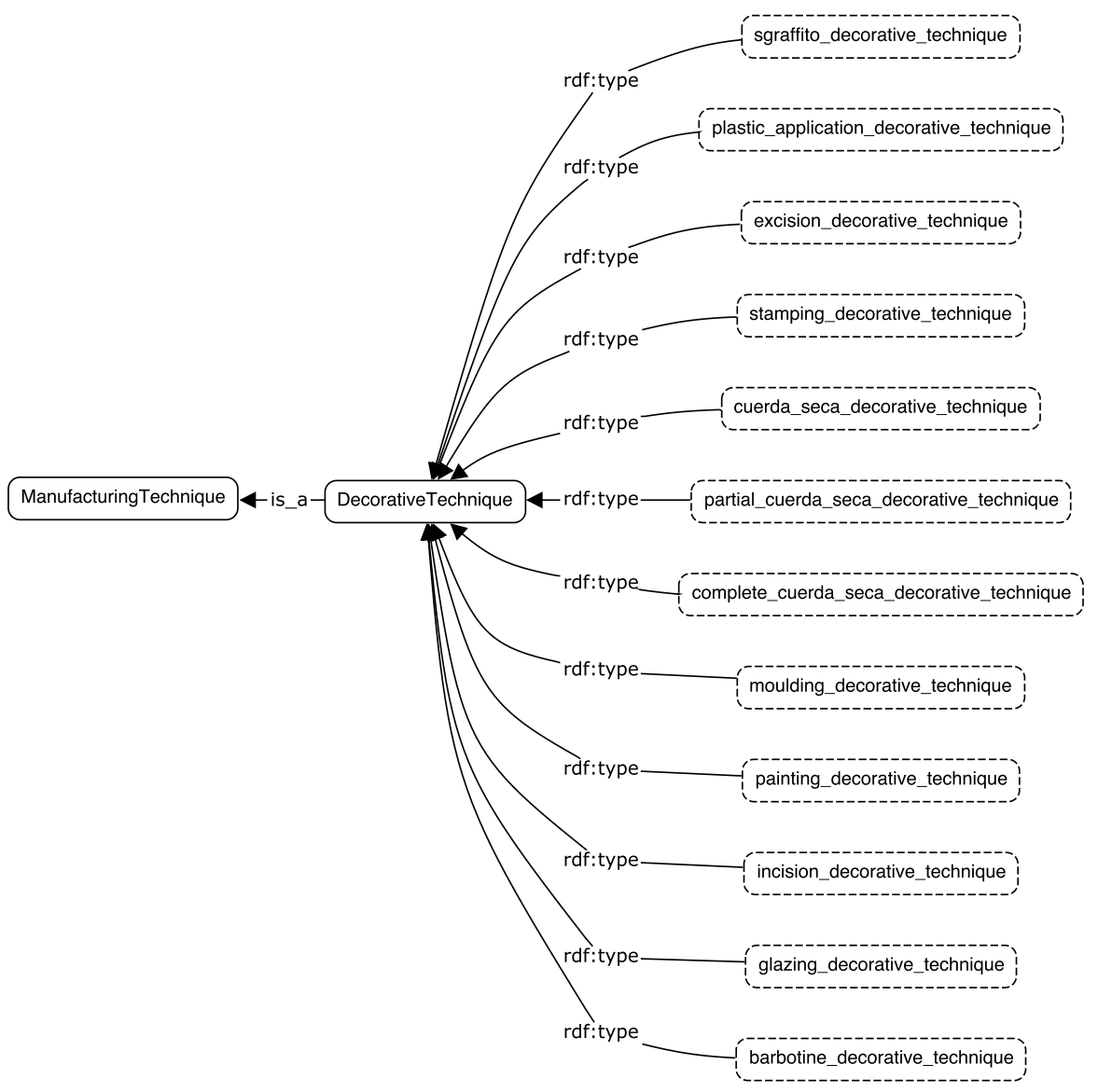

Fig. 11. Decorative techniques in OntoAndalus.

\section{- complete_cuerda_seca_decorative_technique dul:hasPart filling_outlined_spaces_with_glaze- _substance_in_whole_surface}

Both steps of the cuerda seca technique, i.e. drawing motifs and applying glaze, are placed in a sequence through the dul:directlyPrecedes and dul:directlyFollows object properties.

OntoAndalus also includes attributes for the instantiation of manufacturing techniques. The inclusion of these attributes facilitates the description of individual artefacts and of classes instantiating a technique. For example, the class of glazed pottery artefacts should contain in its extension all individuals that participated in a decoration event in which a glazing technique was executed. As a result, the artefacts have the quality of being glazed, which depends on a decoration event. Or, following the quality/attribute distinction, these artefacts have the quality of being decorated which, in turn, has the value of 'glazed'.
OntoAndalus includes object properties for representing these types of attributes, namely hasDecoration, hasFinish, hasShaping and hasFiring, which are specialisations of the dul:hasRegion property. The attributes themselves are modelled as instances of subclasses of dul:PhysicalAttribute (e.g. DecorationAttribute).

\subsection{Artefact instances}

A possible application of OntoAndalus consists on modelling individual artefacts in the domain of interest. The subject of individuals is less prevalent in the literature on terminology. Nevertheless, the representation of so-called 'individual concepts' and the compilation of their designations is featured in the ISO standards on terminology [31, 32].

An important question in this regard is that of uncertain knowledge in artefact descriptions. A notable case in the domain of interest is the artefact known as Vaso de Tavira ('Vessel of Tavira'), having taken its name 


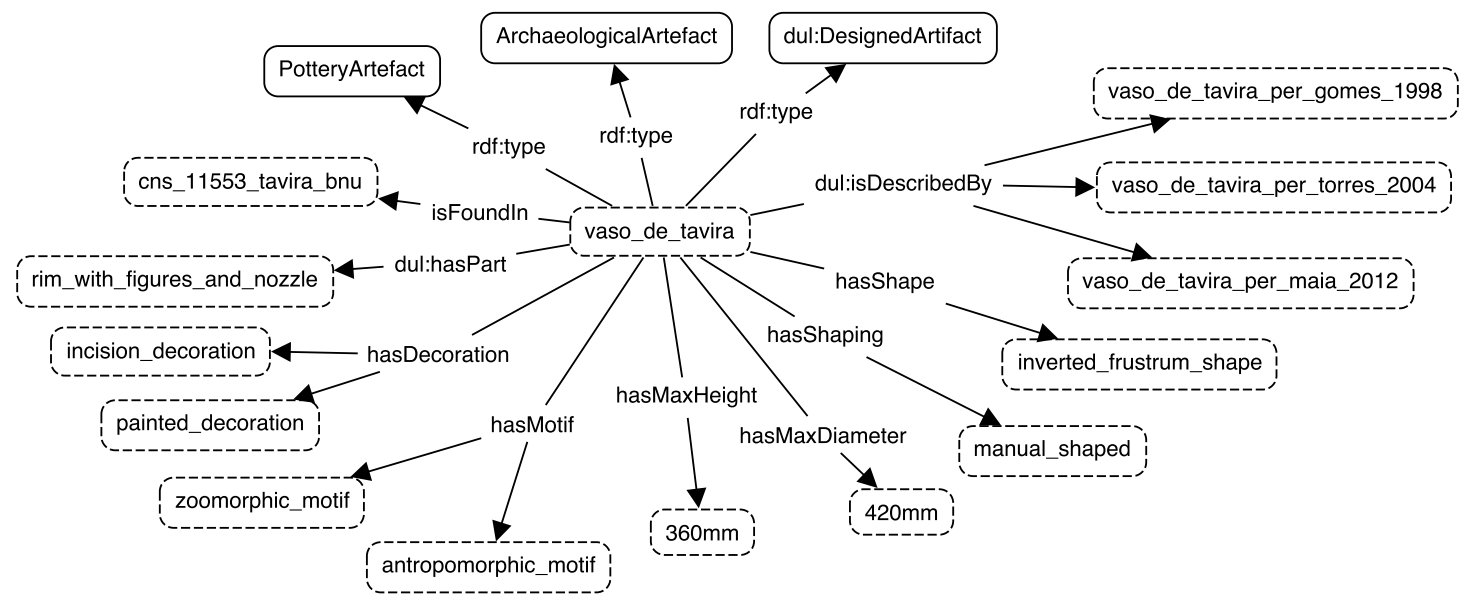

Fig. 12. Formal description of Vaso de Tavira.

from the Portuguese town where it was discovered in the mid 1990's. The artefact has been restored from multiple sherds and is today a staple of the Islamic collection of the Municipal Museum of Tavira.

There is considerable doubt among archaeologists regarding the use and purpose of the object. It has been described as a basin for ritual ablutions [33], as a sweet basil flowerpot which was used as a dowry gift [34] and as a miniature of a palatial water pool [35]. Furthermore, the specialists do not seem to agree on the approximate date of the object's creation: some place it in the 9th century [33], while others place it in the late 11 th to early 12 th centuries $[34,35]$.

Objective (or at least consensual) information about the artefact includes its Islamic origin, the site where it was recovered and several physical qualities. The Vaso de Tavira is generally described as an inverted frustum-shaped object with a maximum diameter of $420 \mathrm{~mm}$ and maximum height of $360 \mathrm{~mm}$. The manufacture techniques employed include the throwing of the vessel itself and the manual shaping of the figures on the rim. The vessel shows painted and incised decoration. The figures on the rim are salient zoomorphic and anthropomorphic motifs. Another salient feature is the elongated nozzle on the rim, which allowed the vessel to be supplied with water through a system of interior channels leading to the orifices in the figures.

The uncontroversial assertions about the artefact pertain to parts (e.g. rim with figures, elongated nozzle), qualities (e.g. size, shape, decoration) and locations (e.g. its provenance). It is also uncontroversial to state that the artefact is an instance of a pottery artefact and of an archaeological find. Other assertions are dependent on the interpretation of the experts and, there- fore, on communication acts. The formal description of Vaso de Tavira is illustrated in Fig. 12.

The three above-mentioned interpretations of the artefact [33-35], are modelled as instances of dul:Description. These descriptions are associated to the artefact through the dul:describes object property. In DUL, a description is understood as a conceptualisation, i.e. as a social object in which concepts are either used or defined, and which can be expressed through an information object (e.g. a journal article).

Fig. 13 shows the relevant elements of a description of Vaso de Tavira. Based on this particular description, the artefact is a flowerpot for growing a particular herb. It played the role of dowry gift somewhere in the late 11 th to early 12th centuries. Since dowry_gift_role and sweet_basil_flowerpot[...] are concepts which have not previously been defined in the ontology, they are related to the description through the dul:defines object property. Lastly, the text containing the description is represented as an instance of the dul:InformationObject class. The latter is linked to the description through the dul:isExpressedBy object property.

The approach shown in this section enables the description of individual artefacts where objective or consensual information is separated from subjective interpretations. The latter are still very much relevant in the domain of interest and, therefore, should not be excluded from the ontology.

As elsewhere in OntoAndalus, this information can serve as the basis for descriptions of ontology elements in a natural language. Descriptions of individual artefacts are, in fact, an important activity in archaeology and cultural heritage. The following is an English description of Vaso de Tavira:
1 


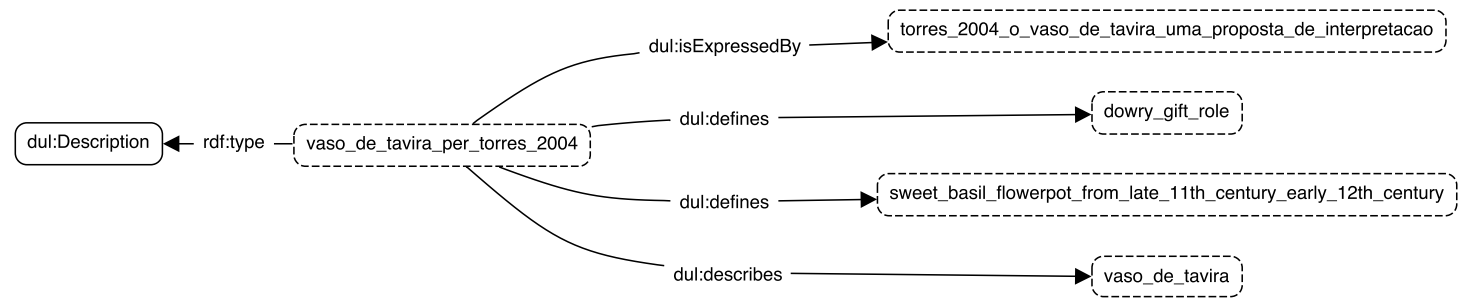

Fig. 13. Relevant elements of a description of Vaso de Tavira.

- Description: Inverted-frustum pottery vessel with painted and incised decoration. Fast potter's wheel execution and figures shaped by hand. Shows zoomorphic and anthropomorphic motifs. It has a maximum height of $360 \mathrm{~mm}$ and a maximum diameter of $420 \mathrm{~mm}$.

- Provenance: Archaeological site of the BNU in Tavira, Portugal (Portuguese National Site Code no. 11553).

- Chronology: Gomes [33] dates the artefact from the 9th century, while Torres [34] and Maia [35] date the artefact from late 11 th to early 12 th centuries.

- Function: According to Gomes [33], the vessel would have been a basin for ritual ablutions. Torres [34] considers it to have been a flowerpot for sweet basil which served as a dowry gift. Maia [35] describes the vessel as a folk miniature of a palatial water pool.

\section{Evaluation}

Following, Gómez-Pérez, technical evaluation is distinguished from user evaluation of ontologies [36]. ${ }^{4}$ The technical evaluation of OntoAndalus during the modelling stage included the use of a reasoner and of the OntoClean method for evaluating subsumption hierarchies. The OWL reasoner HermiT was used within Protégé in order to check the logical consistency of the ontology. Since OntoAndalus is aligned with DUL, via owl:imports, the use of a reasoner ensures that the restrictions defined in DUL are followed in OntoAndalus. For example, any instance of dul:PhysicalObject can only have as parts other instances the same class (or of any class subsumed by dul:PhysicalObject).

\footnotetext{
${ }^{4}$ User evaluation remains an activity for future work, which is dependent on the implementation of OntoAndalus as part of an ontoterminological resource.
}

The OntoClean method, on the other hand, was used in order to evaluate the subsumption hierarchy based on the so-called 'metaproperties' of rigidity, identity, unity and dependence [17]. This essentially avoids abusing the class inclusion relation in ontologies, which typically results from conflating several senses of 'is a'. Following OntoClean led to the realisation that there are several relevant concepts of artefact in archaeology, most notably that of archaeological artefact (one of the basic categories of archaeological data) and that of designed artefact. Since the types of artefacts represented in OntoAndalus are rigid classes (e.g. Lamp, Flowerpot), they cannot be subsumed by ArchaeologicalArtefact, which is anti-rigid (i.e. nothing is necessarily an archaeological artefact). dul:DesignedArtifact was then selected as the top class for the artefact typology, since the former is rigid.

\section{Conclusion}

This article described OntoAndalus, an ontology of pottery artefacts of the al-Andalus which is being developed by using standard Semantic Web technologies. The main purpose of OntoAndalus is to represent domain knowledge within a terminological resource in the domain. It is also thought that OntoAndalus will help further research in archaeology by enabling the ontological analysis of important topics in this domain.

The choice of DUL as a foundational ontology enabled a rich conceptualisation of the domain. In this regard, several assumptions underlying the modelling process were reviewed, starting with the basic categories of archaeological data and moving on to the topics of parthood and quality.

The design patterns regarding artefact types, events and individuals were then exemplified based on relevant case studies in the domain. The modelling of consensual and controversial artefact types is shown, as well as the classification of Islamic lamp types based on multiple criteria of analysis. With regard to events, 
the pottery life cycle is modelled, along with its temporal parts and manufacturing techniques. Finally, the matter of individual artefact descriptions is exemplified through the case of Vaso de Tavira, which further illustrates how several competing interpretations of the artefact can be modelled.

\section{Acknowledgement}

Research financed by Portuguese National Funding through the FCT - Fundação para a Ciência e Tecnologia as part of the project Centro de Linguística da Universidade NOVA de Lisboa - UID/LIN/03213/2019.

\section{References}

[1] C. Roche, Ontoterminology: how to unify terminology and ontology into a single paradigm, in: LREC 2012, ELRA, Paris, 2012, pp. 2626-2630.

[2] I. Durán-Muñoz and M.R. Bautista-Zambrana, Applying ontologies to terminology: advantages and disadvantages, Hermes 51 (2013), 65-77.

[3] R. Temmerman and K. Kerremans, Termontography: ontology building and the sociocognitive approach to terminology description, in: Proceedings of CIL17, Matfyzpress, Prague, 2003.

[4] F. Brin-Henry, R. Costa and S. Desprès, TemPO: towards a conceptualisation of pathology in speech and language therapy, in: Proceedings of the TALN-RECITAL 2019 conference, Toulouse, 2019, pp. 69-80.

[5] C. Roche, R. Costa, S. Carvalho and B. Almeida, Knowledgebased terminological e-dictionaries: the EndoTerm and alAndalus pottery projects, Terminology 25(2) (2019), 262-294.

[6] I. Meyer, D. Skuce, L. Bowker and K. Eck, Towards a new generation of terminological resources: an experiment in building a terminological knowledge base, in: COLING '92 Proceedings of the 14th conference on Computational linguistics, Vol. 3, Association for Computational Linguistics, Stroudsburg, PA, 1992, pp. 956-960.

[7] C. Santos and R. Costa, Domain specificity: semasiological and onomasiological knowledge representation, in: Handbook of terminology, Vol. 1, H.J. Kockaert and F. Steurs, eds, John Benjamins, Amsterdam, 2015, pp. 153-179.

[8] J.C. Carvajal López, The archaeology of al-Andalus: past, present and future, Medieval Archaeology 58 (2014), 318-339. doi:10.1179/0076609714Z.00000000041.

[9] B. Almeida, C. Roche and R. Costa, Terminology and ontology development in the domain of Islamic archaeology, in: Term bases and linguistic linked open data: TKE 2016, H.E. Thomsen, A. Pareja-Lora and B.N. Madsen, eds, Copenhagen Business School, Copenhagen, 2016, pp. 147-156. http: //hal.univ-smb.fr/hal-01354325v1.

[10] B. Almeida, R. Costa and C. Roche, Archaeological classification and ontoterminology: the case of Islamic archaeology of the al-Andalus, Chambéry, 2017. https://hal.archives-ouvertes. fr/hal-01826942.
[11] J. Bugalhão, H. Catarino, S. Cavaco, J. Covaneiro, I.C. Fernandes, A. Gomes, S. Gómez Martínez, M.J. Gonçalves, M. Grangé, I. Inácio, G. Lopes and C. Santos, CIGA: projecto de sistematização para a cerâmica islâmica do Gharb alÂndalus, Xelb 10 (2010), 455-476.

[12] G. Rosselló-Bordoy, Ensayo de sistematización de la cerámica árabe en Mallorca, Institut d'Estudis Baleàrics, Palma de Mallorca, 1978.

[13] G. Rosselló-Bordoy, El nombre de las cosas en al-Andalus: una propuesta de terminología cerámica, Museo de Mallorca, Palma de Mallorca, 1991.

[14] M.A. Musen, The Protégé project: a look back and a look forward, AI Matters 1(4) (2015), 4-12. doi:10.1145/2557001.25757003.

[15] A. Gangemi, Dolce+D\&S Ultralite and its main ontology design patterns, in: Ontology engineering with ontology design patterns: foundations and applications, P. Hitzler, A. Gangemi, A. Janowicz, A.A. Krisnadhi and V. Presutti, eds, IOS Press, Amsterdam, 2016, pp. 81-103.

[16] L.R. Binford, A consideration of archaeological research design, American antiquity 29(4) (1964), 425-441.

[17] N. Guarino and C. Welty, A formal ontology of properties, in: Knowledge Engineering and Knowledge Management Methods, Models, and Tools, R. Dieng and O. Corby, eds, Springer, Berlin, 2000, pp. 97-112.

[18] B. Smith and A.C. Varzi, Fiat and bona fide boundaries, Philosophy and phenomenological research 60(2) (2000), 401-420.

[19] C. Masolo, S. Borgo, A. Gangemi, N. Guarino, A. Oltramari and L. Schneider, WonderWeb deliverable D17: the WonderWeb library of foundational ontologies: preliminary report, 2003.

[20] ICOM/CIDOC, Definition of the CIDOC Conceptual Reference Model. Version 5.0.4, ICOM/CIDOC, 2011.

[21] S. Gómez Martínez, La cerámica islámica de Mértola: producción y comercio, Doctoral thesis, Universidad Complutense de Madrid, 2004.

[22] P.M. Rice, Pottery analysis: a sourcebook, The University of Chicago Press, Chicago, Il, 1987.

[23] R. Casati and A.C. Varzi, Holes and other superficialities, The MIT Press, Cambridge, MA, 1994.

[24] B. Smith, M. Almeida, J. Bona, M. Brochhausen, W. Ceusters and M. Courtot, Basic Formal Ontology 2.0: specification and user's guide, 2015. https://github.com/bfo-ontology.

[25] A. Vallejo Triano and J. Escudero Aranda, Aportaciones para una tipología de la cerámica común califal de Madinat alZahra, Arqueología y territorio Medieval 6 (1999), 133-176.

[26] S. Gutiérrez Lloret, B. Gamo Parras and V. Amorós Ruiz, Los contextos cerámicos altomedievales del Tolmo de Minateda y la cerámica altomedieval en el sudeste de la Península Ibérica, in: Cerámicas tardorromanas y altomedievales en la Península Ibérica, L. Caballero, P. Mateos and M. Retuerce Velasco, eds, CSIC, Madrid, 2003, pp. 119-168.

[27] S. Gómez Martínez, Contenedores de fuego en el Garb alAndalus, in: Actas do $3^{\circ}$ Congresso de Arqueologia Peninsular, Vol. 7, V.O. Jorge, ed., ADECAP, Porto, 2000, pp. 421434.

[28] J. Coll Conesa, J. Martí Oltra and J. Pascual Pacheco, Cerámica y cambio cultural: el tránsito de la Valencia islámica a la cristiana, Dirección General de Bellas Artes y Archivos, Madrid, 1988.
1

5

6

7

8

9 
[29] M.B. Schiffer, Technological perspectives on behavioral change, University of Arizona Press, Tucson, AZ, 1992.

[30] J. Peña, Roman pottery in the archaeological record, Cambridge University Press, Cambridge, MA, 2007.

[31] NF ISO 704, Terminology Work - Vocabulary, AFNOR, La Plaine Saint-Denis, 2009.

[32] ISO 1087-1, Terminology work - vocabulary - part 1: theory and application, ISO, Geneva, 2000.
[33] M.V. Gomes, Portugal islâmico: o estado da arte?, Al-Madan 7 (1998), 19-20.

[34] C. Torres, O Vaso de Tavira: uma proposta de interpretação, Campo Arqueológico de Mértola, Mértola, 2004.

[35] M.G. Maia, Vaso de Tavira, Museu Municipal de Tavira, Tavira, 2012.

[36] A. Gómez-Pérez, Evaluation of ontologies, International journal of intelligent systems 16(3) (2001), 391-409.

1 